\title{
Who Can See My Stuff? Online Self-Disclosure and Gender Differences on Facebook
}

\author{
Manuela Farinosi*, Sakari Taipale** \\ *University of Udine, Italy \\ **University of Jyväskylä, Finland
}

\begin{abstract}
This study investigates the gendered privacy practices and concerns on Facebook, by leaning on the idea of privacy management as a form of digital labour. We analyse if young Facebook users are more concerned about the privacy against other users than against Facebook as a company or against third-party partners. We also analyse if privacy concerns and visibility rules are differentiated by gender. Using a structured online survey, we collected responses from a sample of 813 Italian university students (aged 18-34). Our results show that the respondents have just slightly more privacy concerns against other users than against Facebook, and much less against third-party partners. Unlike a majority of previous studies, we show that women are consistently more concerned about privacy-related risks than men, which can be associated with efforts to take care of digital labour in their everyday life.
\end{abstract}

Keywords: self-disclosure, gender, visibility rules, privacy management, Facebook

\section{Introduction}

Within a relatively short time span, social media applications have intruded into all parts of life and have come to play a crucial role in contemporary culture and society. They have not only reconfigured and transformed older forms of human communication but have also become integrated into daily life, both at ordinary and extraordinary times (e.g., social media use during emergencies, earthquakes, floods, etc.) (Bruns, Burgess, Crawford \& Shaw, 2012). The increasing presence of social media remarkably affects the way we work, study or shop, and it has reshaped social, political and economic relationships (Van Dijck, 2013). Nowadays, individuals, groups and communities discursively engage through and with digital platforms, dissolving spatial, temporal and social boundaries (boyd \& Ellison, 2007). Online and mobile applications offer them the opportunity to create, share and consume content (e.g., text, photos, videos, etc.), as well as to engage in online conversation (Couldry, 2012; Rainie \& Wellman, 2012). To work towards this end, there are many different types of social media, which, despite specific peculiarities, are all characterised by some similar building blocks, such as identity, conversations, sharing, presence, relationships, reputation and groups (Kietzmann, Hermkens, McCarthy \& Silvestre, 2011).

In this article, we focus our attention on the most popular social networking website, Facebook. In particular, we analyse the digital labour and practices of online self-disclosure and management of the visibility rules of young Italian users. These practices are studied, because they are crucial for understanding how young adultsin our case, university students-define who can access specific content and how they conciliate the broadcasting 
of personal information while taking care of their privacy. Moreover, the study of such privacy practices implicitly helps to comprehend how the use of Facebook and social media, in general, alter the concept of privacy itself. With a structured online survey, we collected 1,125 responses from university students and analysed a subsample of 18 to 34-year-old respondents $(N=813)$. We specifically analysed the respondents' main privacy concerns, exploring to which degree personal information is disclosed (i.e., what information is protected, how information is shared, who has access, etc.), whether or not privacy concerns are differentiated by gender and if those concerns focus more on other users than on Facebook as a company or on third-party partners.

We decided to analyse the Italian context mainly for two reasons. First, available literature reveals that most previous studies on this topic have been conducted in the context of different countries; in particular, among American college students (Hollenbaugh \& Ferris, 2014; Lewis, Kaufman \& Christakis, 2008; Stutzman, Gross \& Acquisti, 2013; Tufekci, 2008), and little is known about Italy. Second, the penetration rate of the Facebook platform is comparatively high among Italian internet users. In Italy, in fact, Facebook represents the most popular online social networking service in terms of diffusion, with 25 million active users. Considering that, on a monthly basis, Italian internet users were estimated to be 28.9 million, which means a penetration rate of $86 \%$ (Cosenza, 2015). In particular, in regards to the target population of our study, it seems that Facebook users-between the ages of 18 and 34 years-represent about 42\% of all Italian users (Facebook, 2015). ${ }^{1}$

The paper begins with a review of scholarly literature of online privacy management and gender differences on Facebook. It then describes the research methodology, before moving to the presentation of empirical results. Finally, the essay discusses the findings and draws some conclusions that can inform future research needs.

\section{Privacy Concerns on Facebook}

Nowadays, social media accounts for a large majority of the digital content, generated and distributed every day online by ordinary people. It is characterised by four technical properties (i.e., persistence, search-ability, replicability and scalability) and three specific dynamics (i.e., invisible audiences, collapsed contexts and the blurring of public and private), which users should take into account when participating in the online sphere (boyd \& Ellison, 2007). These features affect the interaction in online environments and can remould practices of information disclosure and control over privacy settings (Bartsch \& Dienlin, 2016; Bazarova, 2012; Chambers, 2013; Liu, Yao, Yang \& Tu, 2017).

Previous studies have shown that there are different levels of concern about one's own privacy, which depend on a person's individual perceptions and values (Joinson \& Paine, 2007). Privacy is not an absolute but rather a subjective and contextual value, and the right to privacy is based on an array of cultural and social practices and understandings of the private sphere (Nissenbaum, 2004; Soffer \& Cohen, 2014). The literature suggests that the reasons behind why some people take measures to restrict access to their information, versus the reasons why others do not, vary. The effect of different aspects, such as gender, cultural background, digital skills and

\footnotetext{
${ }^{1}$ This data was extracted using Facebook's advertising tool. It is primarily intended to be used by advertisers to create and target their campaigns. However, it can also be used to research the number of people within a selected group, based on where they live, their age, their gender, their relationship status, etc. For more detailed information on how the tool works, visit the following official Facebook page: https://www.facebook.com/business/a/online-sales/ad-targeting-details.
} 
level of online activity, has been analysed (Bellman, Johnson, Kobrin \& Lohse, 2004; Cho, 2007; Fogel \& Nehmad, 2009; Lewis et al., 2008; Sun \& Wu, 2012; Thelwall, 2011; Weiqin, Campbell, Kimpton, Wozencroft \& Orel, 2016; Youn \& Hall, 2008).

According to Waters and Ackerman (2011), for example, the practice of managing Facebook's privacy settings is shaped by a set of principles that govern disclosure of personal information, such as culture, motivation, context, experience and risk-benefit ratio. Among the main factors that influence information revelation, Gross and Acquisti (2005) identify: (a) the perceived benefits of revealing a select set of data to strangers; (b) the influence of peer pressure and 'herding' behaviour; (c) a careless attitude regarding personal privacy; (d) ignorance about the possible consequences of online self-disclosure; (e) trust in others or the host site; and ( $f$ ) required acceptance of the privacy settings. As highlighted by Stutzman et al. (2013), 'Because social network sites thrive on peer-produced content, disclosure is often concomitant with site use' p. 10). Also, Ledbetter (2009), exploring the motivations that influence media-use patterns and foster online interpersonal communication, identifies social connection and self-disclosure as the fundamental motivations of influence.

Given that the desire to communicate is a primary driver, sociability and privacy can appear as conflicting needs on Facebook, in the light of the deep rootedness in the activities and sharing options that the platform's design encourages. Social benefits that Facebook gives in exchange for status updates, photos and videos are appealing yet problematic (Awan \& Gauntlett, 2013). Social media alters traditional practices of visibility and information sharing, and there is a discrepancy between disclosures from the context of face-to-face interaction to that of computer-mediated communication. In offline contexts, people are used to maintaining multiple relationships, ranging from weak ties to strong links, which exist in different social contexts (e.g., work, school, family, hobby, sport, etc.) (Goffman, 1959). On the contrary, online, there is a 'networked context', characterised by a lack of the traditional spatial, social and temporal boundaries and a simultaneous presence of many individuals coming from different contexts, and this provokes the so-called 'collapsed contexts' effect (boyd \& Ellison, 2007; Marwick \& boyd, 2014). In this sense, the platform's settings, in conjunction with personal attitudes and behaviours, represent a critical component in determining how and with whom users interact and how they selectively control access to information about themselves (Farinosi, 2011; Hogan, 2010).

In the networked context of Facebook, the regulation of social interaction can occur in a number of ways (e.g., users may limit access to their profile to 'Friends only'), and people can also decide to share content, updates or photos only with a subset of their total network, employing segmented privacy settings (i.e., a specific friend list) (Ellison, Vitak, Steinfield, Gray \& Lampe, 2011; Stutzman et al., 2013). Furthermore, users adopt a range of tactics and strategies to protect and manage their online presence, including: self-censorship, social steganography and withdrawal of content (Acquisti, Brandimarte \& Loewenstein, 2015; Lampinen, Lehtinen, Lehmuskallio \& Tamminen, 2011; Marwick \& boyd, 2014). Nevertheless, they are not always prudent about the proportions of personally identifiable information they share and the potential consequences this can have in their offline life (Waters \& Ackerman, 2011).

In addition, previous studies found that keeping a social network purposefully small, due to privacy concerns, and by using advanced privacy settings, is considered as a barrier to using Facebook for information needs (Vitak \& Ellison, 2013). Likewise, the research conducted by Palmieri, Prestano, Gandley, Overton \& Zhang (2012) has shown that people often feel less uncertain about a user who discloses more than others, highlighting how the 
depth and breadth of self-disclosure by users seems to increase group predictability and interdependence. At the same time, some analyses have also found that people adopting segmented privacy settings report bigger networks and perceive higher bonding and bridging of social capital than users who do not employ this feature (Ellison et al., 2011).

Even if Facebook allows users to change their personal settings to manage who can view their profile and what content is viewable, the control over personal information can be extremely difficult online, because it can be relinquished without the user knowing it (Waters \& Ackerman, 2011). The basic problem with Facebook disclosure is that all the conversations and user-generated content (UGC) takes place on a commercial platform that stores not only the online communications but also personal likes of users, location-data, search-history, reading-behaviour and much more. Given that Facebook is a commercial organisation, its economic goal is to achieve financial profit, in particular, through targeted and personalised advertising that is based on sophisticated data-mining techniques and the sale of personal data and behaviours of its users (Fuchs, 2012). However, only a few Facebook users are aware of these dynamics, while most of them believe that their conversations and behaviours remain privately held and free from intrusion by the government or advertising companies (Bedi, 2013). As highlighted by boyd (2012):

most people are unaware that their data is aggregated with others to construct portraits of individuals that predict their interests based on others' habits. Our interpreted selves aren't simply the product of our own actions and tastes; they're constructed by [recognising] similar patterns across millions of people. (pp. 348-349)

Some studies have also pointed out that people are more concerned about being exposed to people that they know in offline-life than having their information accessed by third-party companies (Raynes-Goldie, 2010). This means that social privacy is typically of greater concern to people than institutional privacy. A similar finding also emerged from the analysis conducted by boyd (2014), which highlights that young people are typically not so concerned with governments and corporations as politically conscious adults are. Instead, teenagers are seeking privacy from their parents, teachers and other close-by persons who hold power over them. This desire for privacy does not rule out the other desire to be in public. According to boyd (2014), in fact, young people appreciate being in public, gathering and socialising in public spaces; yet, this does not mean that they would like to publish all their sayings and doings to the general public. Therefore, we define our first hypothesis as follows:

Hypothesis 1: Young people are more concerned about the privacy against other users than against Facebook as a company or against third-party partners.

\section{Gender Differences in Privacy Management}

Given that information sharing can also be potentially connected with safety and certain potential privacy riskssuch as damage to reputation due to rumours and gossip, unintentional disclosure of personal information, 
vulnerability to stalkers, cyberbullying, hacking, identity theft, use of private data by a third party, etc. (Lewis et al., 2008; Palfrey, Sacco \& boyd, 2008)-the privacy management, as a form of digital labour, may mirror some gendered roles and practices in societies. The traditional division of domestic work has meant that women have taken a greater responsibility for immaterial, typically non-monetised tasks. This has given them the role of organisers and maintainers of the private sphere (Fortunati, 1996, 2007). In this historical context, privacy management can be considered as another form of immaterial labour.

Previous research about social network sites has investigated gender differences regarding online privacy concerns and privacy protection behaviours, but the studies have shown controversial results. In general, women are more concerned about others accessing their personal information, and they perceive more risk online and more severe consequences of privacy loss than men (Fogel \& Nehmad, 2009; Hoy \& Milne, 2010; Tufekci, 2008). However, if women tend to be more worried than men and adopt more precautions to protect their privacy, then they will likely post more content, be more active users and open their profile to more friends (Thelwall, 2009). For example, in their examination of undergraduate Facebook profiles, Kolek and Saunders (2008) found that college women, with the exception of posting a telephone number, disclose information about themselves at a greater level than men across all the sections coded in the analysis.

In terms of online self-disclosure, Tufekci (2008), has reported significant gender differences, in particular with respect to the phone number, while exploring the practices adopted by a sample of college students $(N=704)$ to negotiate boundaries between public and private on Facebook. Female students were less likely to reveal their number, but more likely to indicate their religion and their favourite music and books than males. On the other hand, men were more likely to think about a corporation or government looking at their profile than women were. Similarly, a study conducted by Acquisti and Gross (2006) indicates that women are less likely to post their sexual orientation, address and phone number, but finds no gender differences regarding political view and date of birth. On the contrary, an analysis of Canadian students shows contrasting findings and reveals no significant difference in information disclosure between women and men, with the exception of a greater publication of information about political affiliation and religion by men (Nosko, Wood \& Molema, 2010). Also, Brandtzaeg (2015), analysing more than 21 million Facebook users in ten countries, found that men use Facebook more for informal and political reasons and are more supportive of political driven pages than women.

Concerning privacy protection behaviours, Hoy and Milne (2010), analysing 589 respondents (from 18 to 24 years old), have found that women are significantly more concerned than men about their privacy being invaded on Facebook and, consequently, engage more frequently in privacy-related behaviour. In addition to controlling privacy settings, they adopt several protection strategies, such as reading the privacy policy of Facebook prior to joining, reviewing the personal settings, monitoring their profile, un-tagging photos and deleting messages from their profile wall ${ }^{2}$, being careful about whom they friend, taking care in joining groups, controlling privacy settings so that only friends can see their profile and using the 'friends list' control feature. Similar findings are reported by Thelwall (2011), who highlights that for females 'the benefits of greater social needs and better social communication skills outweigh the greater physical security and harassment fears (p. 261), so they are

\footnotetext{
${ }^{2}$ At the time of the research, the 'wall' was the area on the Facebook platform where people can post their thoughts, pictures or videos. Later Facebook renamed it 'timeline'.
} 
more privacy-conscious when using social platforms and adopt a wide range of privacy protection strategies, such as giving incorrect information.

On the contrary, boyd and Hargittai (2010), investigating a cohort of university students (ages 18 and 19), have observed only a few gender differences in how frequent Facebook users manipulate privacy settings and take measures to restrict access to their Facebook profiles. This finding is significant, 'Since this is one of the few domains in which a gender difference does not exist for a confidence measure, it is important to reflect on what may be causing such uncharacteristic confidence among women (boyd \& Hargittai, 2010, Discussion and conclusion section, para. 6).

There are also many other researchers who have not found substantial or consistent gendered discrepancies in the management of privacy settings on Facebook. For example, Vitak and Ellison's (2013) qualitative study on the use of Facebook by 18 US-based adults was not able to detect obvious dissimilarities across gender or age. Waters and Ackerman (2011), who conducted a survey of college students to explore the motivations of voluntary disclosure on Facebook, found that the only significant gender difference is that women are more motivated to disclose private information for storing information or using it for entertainment reasons than men. For the other dimensions (i.e., information sharing, keeping up with trends, showing off, relationship management, well-being and habitual behaviour), males and females tend to regard their motivations as being similar. As the previous findings related to gender difference are ambiguous, we hypothesise that:

Hypothesis 2: Privacy concerns against other users, Facebook and third parties are inconsistent or not differentiated by gender.

\section{Methodology and Data}

\section{Data}

In this research, we draw on questionnaire-based survey data to examine users' level of awareness of privacy issues and explore if there are any gender differences in the degree to which personal information is disclosed. The data for this study was collected by a structured online survey-prefaced with an informed consent form, which briefly defined the purpose of the investigation-over a six-week period, starting in mid-April and ending in late May 2012. The questionnaire consisted of 44 single and multiple-choice questions, which were selected mainly by reviewing the literature and adopting and adapting questions from previous studies (Bach et al., 2011; Lenhart et al., 2011; Madden \& Smith, 2010). The link to the survey was distributed to all the students of the University of Udine ( $N=16,396$-source: https://nuva.uniud.it/scon/ateneo-in-cifre/iscritti), who were invited via e-mail to the official e-mail address with academic domain name (i.e. surname.name@spes.uniud.it) to participate in the study. The total number of responses amounted to 1,125; however, in this study, we focus on a sub-sample of 813 respondents who: (1) reported that they have a Facebook account and (2) whose age ranged from 18 to 34 years. 


\section{Measures}

The distributions of the measures applied in our statistical analyses are illustrated in Table 1 . In the following sections, we present the dependent and independent variables as well as the socio-demographic measures included in the models.

Table 1: Characteristics of the Sample

\begin{tabular}{lc}
\hline & Total \% (N) \\
\hline Gender & \\
- Male & $41.3(336)$ \\
- Female & $58.7(477)$ \\
Age & \\
- 18-25 & $82.8(673)$ \\
- 26-34 & $17.2(140)$ \\
Marital status & \\
- Single & $92.5(752)$ \\
- Married & $2.7(22)$ \\
- Others & $4.8(39)$ \\
Education & \\
- High School Diploma & $63.3(514)$ \\
- Bachelor's degree & $26.8(218)$ \\
- Others (higher) & $10.0(81)$ \\
Facebook time & \\
- Less than 1 hour per week & \\
- Approx. 1 hour per week & $8.5(69)$ \\
- Everyday, less than 1 hour & $14.2(115)$ \\
- Everyday, 1 hour or more & $48.6(395)$ \\
Visibility of others' posts on the wall ("Who can see what other & \\
people publish on your wall") & $28.7(233)$ \\
- All & \\
- Friends of friends & $14.8(120)$ \\
- Friends & $16.4(133)$ \\
- Only specific people/lists & $16.1(131)$ \\
- Only me & $52.7(428)$ \\
- I don't know & $17.4(141)$ \\
Privacy index & $56.4(458)$ \\
- Little privacy & $5.9(48)$ \\
- Somewhat privacy & $2.0(16)$ \\
- Much privacy & \\
- Very much privacy & \\
\hline
\end{tabular}




\section{Main Privacy Concerns}

Dependent variables, the main privacy concerns, were obtained by using the following three questions: (1) 'From 1 to 5 , how much are you interested in protecting your privacy against the company (Facebook)?' (Mean ( $M$ ) = 4.1; Standard Deviation $(S D)=1.1$ ); (2) 'From 1 to 5 , how much are you afraid of a potential breach of your privacy by third parties?' $(M=3.5, S D=1.2)$; and (3) 'From 1 to 5 , how much are you afraid that someone uses the personal information you have posted on Facebook?' $(M=3.3 ; S D=1.3)$.

\section{Privacy index}

To investigate what and with whom young adults want and do not want to reveal on Facebook, we focus on the analysis of the questions related to their profile details. We asked, 'Who can see the following information?' Altogether, 26 items were extracted from the profile information page and the favourites list on Facebook and presented to the respondents, such as: current city, hometown, date of birth, relationship status, relatives, employer, university attended, religion, address of residence, email address, mobile number, instant messaging username and website address. The following answer choices were supplied on the basis of what Facebook suggests: 'All', 'Friends of friends', 'Friends', 'Only specific people or lists' or 'Only me' (the latter is used both in the sense of 'not visible to anyone else' and 'not published on Facebook').

The privacy index was created to condense this large amount of data. At the first phase, we attributed the value of 1 to the answer choice, 'All', and the value of 0 to all other answer modalities of the 26 original items. Next, all these variables were summed to yield a total privacy index value that ranged from 0 to 26 . At the second phase, the values of the privacy index were reduced into four categories: (1) 'Little privacy' (index values, from 13 to 26 , equalled 14.8\%); (2) 'Somewhat privacy' (index values, from 5 to 12 , equalled 16.4\%); (3) 'Much privacy' (index values, from 1 to 4, equalled 16.1\%); and (4) 'Very much privacy' (index value, 0, equalled $52.7 \%$ ). It was necessary to build and use the index variable, since including all 26 original items in a multivariate statistical model would have had negative bearings on the model performance.

\section{Visibility of others' posts on the wall}

We also asked, 'Who can see what other people publish on your wall?', to study if the respondents have any control over what other people publish on their walls and whether this is connected to their privacy concerns or not. The majority of the respondents (56.4\%) reported that it is only 'Friends' who can see the posts published by others, while only less than a tenth ( $8.4 \%$ ) disclosed this information to all others. It is also worth highlighting that just $2 \%$ decided to hide other users' posts on their walls. There were also $10 \%$ of users who declare to not know who can see this information. 


\section{Facebook time}

To understand how intensively our respondents use Facebook, we asked: 'How much time do you spend on Facebook approximately?' The time spent was obtained with eight categories, which were combined into four to ensure a sufficient number of answers in each. Of all respondents, $8.5 \%$ reported that they spend less than one hour per week on Facebook, and 14.2\% reported that they spend approximately one hour per week on Facebook. Almost a half of the sample, $48.6 \%$, accessed Facebook every day for less than one hour, and $28.7 \%$ used it every day for more than one hour.

\section{Socio-demographic variables}

The sub-sample consists of $41 \%$ of men and $59 \%$ of women. The age was measured with six pre-determined categories, two of which were included in the sub-sample. Regarding age, $82 \%$ were 25 years old or younger, and $18 \%$ were between 26 and 34 years old. By marital status, $92 \%$ were singles, $4 \%$ co-habitants and $3 \%$ married. The rest were either separated or widowed. Educational attainments were measured with five predetermined answer choices. There were $63 \%$ of respondents with a high school diploma, $27 \%$ with a Bachelor's degree, $9 \%$ with a specialist degree and less than $1 \%$ with a Master's or a PhD degree.

\section{Statistical Procedures}

In terms of statistical tools, we applied a cross-tabulation of categorical variables with a Chi-square test, Analysis of Variance (ANOVA) and General Linear Model (GLM) to study privacy concerns. Chi-square tests were applied to study whether the observed differences between men and women, in cross-tabulations, were due to chance or not. A series of ANOVAs was carried out to test if the mean values of the privacy concerns against other users, Facebook and third-party partners were different for men and women. We report $F$-ratios and $p$-values to test Hypothesis 1. A GLM model was built to obtain answers to Hypothesis 2 and gain additional support for Hypothesis 1. As a flexible statistical tool, GLM modelling allowed us to test three different privacy concerns at the same time. It also made possible including a range of explanatory variables with different answering scales in the same model.

\section{Results}

Before testing our hypotheses, we want to illustrate the different forms of self-disclosure on Facebook, which emerged from our survey of the Italian college students. Figures 1 and 2 show that the least often shared information are mobile phone number, postal address of residence and usernames of instant messaging services. 
More than half of the respondents prefer to keep this type of contact information private and not share it with their Facebook friends. The only form of contact information that respondents are inclined to make public is the e-mail address, which is usually available already online and findable via search engines. On the contrary, the level of self-disclosure is high for information, such as religion, date of birth and hometown, which are made public to all other users by more than $30 \%$ of the respondents. Concerning relationship status and relatives, the level of privacy is already a bit higher. Between $15.1 \%$ and $22.0 \%$ of our respondents share such information with all other Facebook users.

Figure 1: Self-disclosure on Facebook among male users.

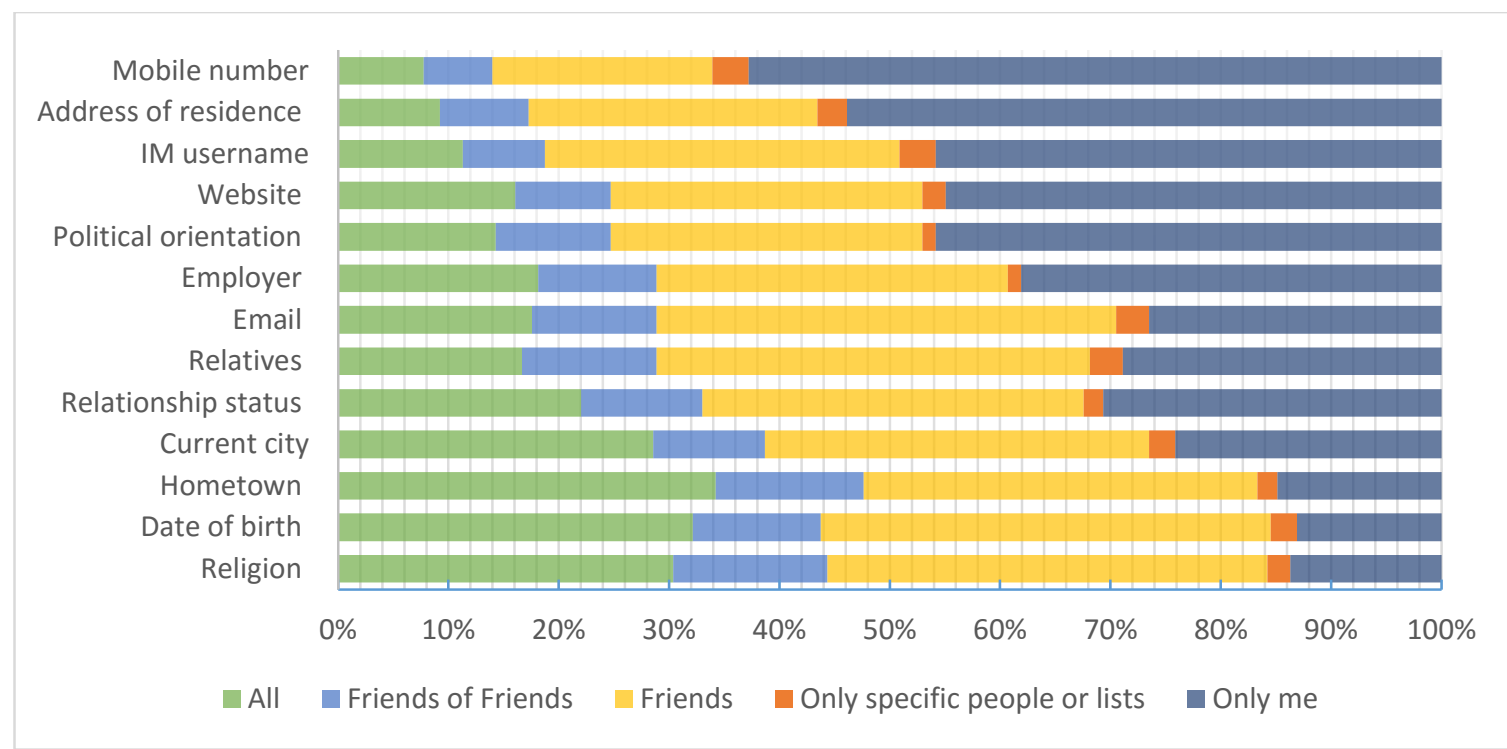

Figure 2: Self-disclosure on Facebook among female users.

Mobile number Address of residence

IM username Website Political orientation Employer Email Relatives Relationship status Current city Hometown Date of birth Religion

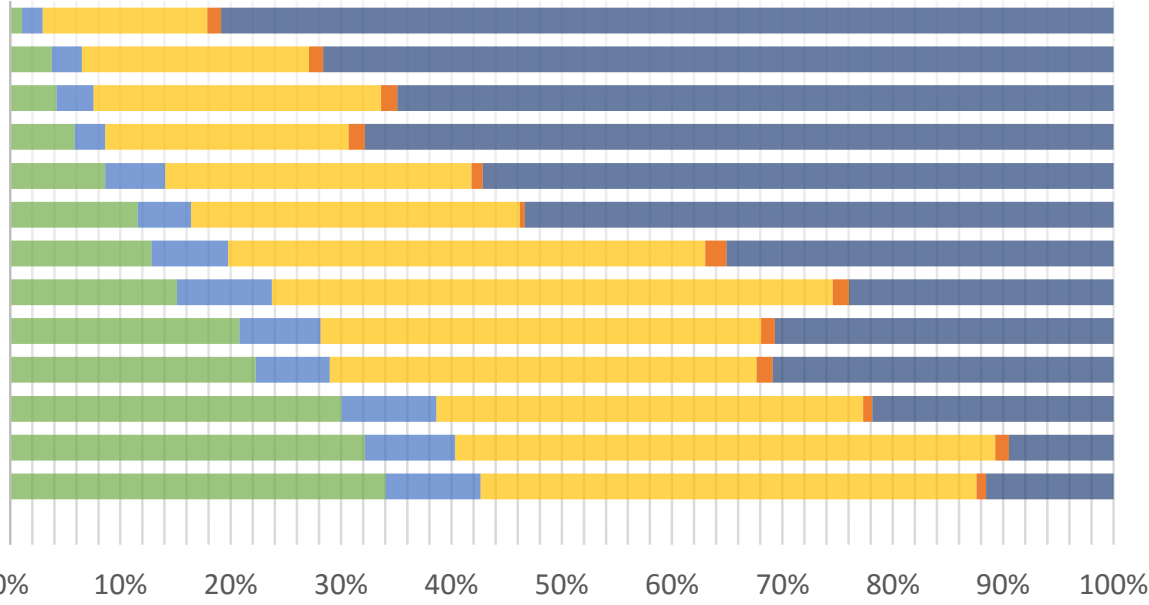


Figures 1 and 2 also reveal that almost all of the investigated items are differentiated by gender. The statistical significance of gender differences was tested with the Chi-square test ${ }^{3}$. In line with previous studies (Acquisti \& Gross, 2006; Kolek \& Saunders, 2008; Tufekci, 2008), the contact information presents the most pronounced gender differences. Women are more careful not to reveal their contact details to others, especially the mobile phone number. Gender comparisons also show that men are more willing to share their political views and working status on Facebook than women (Brandtzaeg, 2015; Nosko et al., 2010). However, it is good to bear in mind that the sample is composed of students, who are typically not fully involved in the labour market. The two items that do not present statistically significant gender differences are the date of birth and e-mail address. Only a small minority of the respondents (from $1.1 \%$ to $3.3 \%$ ) use 'Friend lists' to control the visibility of content and restrict it to a specific group of people on Facebook.

Next, we investigate the levels of privacy concern according to gender. From Table 2, it can be noticed that the highest level of concern is experienced toward other users. This is well in line with the previous results, arguing that young people are more concerned about their peers than institutional privacy (boyd, 2014; Raynes-Goldie, 2010). Table 2 also shows that the concerns considering Facebook as an institution are almost at the same level as the concerns about other users. Third-party partners clearly provoke less worry among young people. Furthermore, ANOVA tests indicate that there are some gender differences, regarding privacy against other users and privacy against third parties. In these two cases, women are more worried than men. In respect to Hypothesis 1, it can be concluded that young adults have slightly more privacy concerns against other users than against Facebook, and much less against third-party partners. Women's privacy concerns, in general, are higher than men's, but this will be investigated further in the following section. After all, Hypothesis 1 can be accepted with some caution.

Table 2: Levels of Privacy Concerns

\begin{tabular}{l|l|l|l|l|l|l|l|l|l} 
& \multicolumn{9}{|l|}{ Privacy against other users* } \\
& \multicolumn{9}{|l|}{$\begin{array}{l}\text { Privacy } \\
\text { Facebook }\end{array}$} \\
& M & SD & N & M & SD & N & M & SD & N \\
\hline \multirow{3}{*}{ Male } & 4.04 & $(1.11)$ & 336 & 4.03 & 1.25 & 336 & 3.29 & $(1.21)$ & 336 \\
Female & 4.37 & $(0.91)$ & 476 & 4.17 & 1.10 & 476 & 3.56 & $(1.18)$ & 476 \\
Total & 4.23 & $(1.00)$ & 812 & 4.11 & 1.17 & 812 & 3.45 & $(1.20)$ & 812 \\
\hline
\end{tabular}

Notes. $* F=22.034, d f=1, p=0.000 ; * * F=2.857, d f=1, p=0.091 ; * * * F=10.087, p=0.002$.

\footnotetext{
3 The results of Chi-square tests for gender differences are as follows: Religion $\left(X^{2}=10.222, d f=4, p=0.037\right)$; Date of birth $\left(X^{2}=5.00, d f=4, p=0.287\right)$; Hometown $\left(X^{2}=12.260, d f=4, p=0.016\right)$; City where you live now $\left(X^{2}=10.825, d f\right.$ $=4, p=0.029)$; Relationship status $\left(X^{2}=10.758, d f=4, p=0.029\right)$; Relatives $\left(X^{2}=12.485, d f=4, p=0.014\right)$; Email $\left(X^{2}\right.$ $=13.043, d f=4, p=0.011)$; Employer $\left(X^{2}=29.986, d f=4, p=0.000\right.$; Political orientation $\left(X^{2}=17.075, d f=4, p=\right.$ $0.002)$; Website $\left(X^{2}=54.742, d f=4, p=0.000\right)$; Instant messaging usernames $\left(X^{2}=38.449, d f=4, p=0.000\right)$; Address of residence $\left(X^{2}=35.449, d f=4, p=0.000\right)$; Mobile number $\left(X^{2}=34.449, d f=4, p=0.000\right)$.
} 
In Table 3, we present the results of a multivariate analysis, executed by applying GLM. With this analysis, we aimed to further investigate which socio-demographic factors and which factors regarding the volume of Facebook use and privacy practices are related to the three main privacy concerns: (1) concerns against other users, (2) concerns against Facebook as a company and (3) concerns against third-party partners. The only variables that were statistically significant were included in the final model that is presented in Table 3 . While designing the model, we found that the following factors were not associated with the response variables (i.e., age of respondents, marital status, highest completed level of education and the perceived level of expertise as a Facebook user). We also tested whether or not the questions, 'Who can post on your wall?' and 'Who can send you Facebook messages?', would work as predictors to discover if they were not related to the dependent variables. Interaction effects between gender and other independent variables were also studied; yet, none were found. The models predict between $5 \%$ and $23 \%$ of total variance of dependent variables as measured with Adjusted R-squares.

Table 3: General Linear Model for Privacy Concerns

\begin{tabular}{|c|c|c|c|c|c|c|}
\hline \multirow[b]{2}{*}{ Independent variables (ref. category) } & \multicolumn{2}{|c|}{ Against other users } & \multicolumn{2}{|c|}{ Against Facebook } & \multicolumn{2}{|c|}{$\begin{array}{l}\text { Against the third- } \\
\text { party partners }\end{array}$} \\
\hline & B & sig & B & sig & B & sig \\
\hline Sex (Female) & & & & & & \\
\hline $\begin{array}{l}\text { - Male } \\
\text { Facebook time (Less than } 1 \text { hour per } \\
\text { - Approx. } 1 \text { hour per week }\end{array}$ & -.253 & $.000 * * *$ & -.105 & $.000 * * *$ & -.240 & $.005^{* *}$ \\
\hline - Everyday, less than 1 hour & -.319 & $.019 *$ & -.283 & .104 & -.199 & .267 \\
\hline - Everyday, 1 hour or more. & -.325 & $.005^{* *}$ & -.273 & .068 & -.226 & .143 \\
\hline & -.356 & $.004 * *$ & -.328 & $.038^{*}$ & -.362 & $.027 *$ \\
\hline $\begin{array}{l}\text { Who can see what other people publis } \\
\text { wall? (All) }\end{array}$ & & & & & & \\
\hline - Friends of friends & .957 & $.000^{* * *}$ & .641 & $.000 * * *$ & .367 & $.044 *$ \\
\hline - Friends & 1.085 & $.000 * * *$ & 696 & $.000 * * *$ & .600 & $.001 * *$ \\
\hline - Only specific people/lists & 1.317 & $.000 * * *$ & .839 & $.000 * * *$ & 1.000 & $.000 * * *$ \\
\hline - Only me & 1.383 & $.000 * * *$ & .953 & $.004 * * *$ & 1.083 & $.001 * *$ \\
\hline
\end{tabular}




\begin{tabular}{ll|l|l|l|l|l} 
- I don't know & .311 & $.040 *$ & .143 & .460 & .073 & .751 \\
Privacy index (Little privacy) & & & & & & \\
- Somewhat privacy & .208 & .075 & .080 & .594 & .079 & .606 \\
- Much privacy & .311 & $.011^{*}$ & .019 & .905 & -.053 & .745 \\
- Very much privacy & .474 & $.000 * * *$ & .266 & .045 & .007 & .957 \\
\hline Adjusted R-square & .234 & & .060 & & .049 & \\
$N$ & 812 & & 812 & & 812 & \\
\hline
\end{tabular}

Note: Only statistically significant predictors are included in the model.

Regarding the privacy concerns against other users, it can be confirmed that women experience such concerns more than men. Furthermore, it turns out that the more time spent on Facebook is associated with a lower level of concern that other users would breach their privacy. It seems that a deeper knowledge of Facebook develops as users gain more confidence in managing its privacy settings and spend more time using it. This behaviour could be translated into fewer concerns about the intentions of other users.

There is also a logical connection between respondents' social privacy concerns and the categories of individuals with whom they share the information on the wall. Compared with the respondents who share their wall with all, privacy concerns toward others increase gradually when respondents limit the social circle with which they share the wall information. In this respect, users who do not share information on their wall with anyone are the most concerned. Finally, the privacy index indicates that higher scores on the privacy index are related to higher concerns toward other users in privacy issues. It is rational that people who are most worried that other users may violate their privacy share the least personal information (e.g., address, e-mail addresses, phone number, etc.) about themselves on their Facebook profile page with all others.

Regarding privacy concerns towards Facebook as a company, our multivariate model confirms that, also in this respect, women experience more concerns than men. The amount of time spent on Facebook is not a major issue here. Only the heavy users who spend one hour or more on Facebook every day are slightly less concerned about Facebook's possible privacy violations than the light users, who use Facebook less than one hour per week. The more privacy concerns respondents have towards Facebook, the more they limit the social circle that can see what they publish on their walls. Interestingly, the privacy index is not related to this dependent variable at all, referring to the fact that the respondents do not think that Facebook would misuse the personal information they have inserted in their Facebook profiles.

In this data, third parties, as the source of privacy concerns, are very similar in relation to predicting factors as concerns toward Facebook as a company. Again, women experience more concern toward third-party privacy violations than men. Only respondents that spend the highest amount of time on Facebook are a bit less concerned than respondents who use Facebook only occasionally (i.e., less than one hour per week). Lastly, it can also be stated that the privacy index is not related to worries against the third parties. Based on these 
analyses and in response to Hypothesis 2, it can be safely stated that women are more concerned about their privacy than men, and, consequently, Hypothesis 2 shall be rejected.

\section{Discussion and conclusions}

In this article, we have investigated the different forms of self-disclosure on Facebook among Italian university students. While previous studies, conducted in other countries, emerged ambiguous results on gendered privacy practices and concerns (boyd \& Hargittai, 2010; Lewis et al., 2008; Nosko et al., 2010; Stutzman et al., 2013; Tufekci, 2008; Vitak \& Ellison, 2013; Waters \& Ackerman, 2011), this research shows that Italian women are consistently more aware of the online protection of their private sphere than Italian men.

Our results point out that women experience more concerns about the invasion of the private sphere, not only by other users but also by Facebook itself and its third-party partners. Similar to previous studies, conducted in other countries (Acquisti \& Gross, 2006; Kolek \& Saunders, 2008; Tufekci, 2008), the results also show that Italian women tend to share less personal contact information (i.e., mobile phone and postal address) and adopt different practices of information disclosure than Italian men. The roots of the gender differences can be associated with several factors. For instance, women perceive different dangers than men and have a higher level of risk perception (Gustafson, 1998; Hoy \& Milne, 2010; Thelwall, 2011). Our results show that women are more concerned than men about revealing any kind of personal information or content and tend not to publish their contact information as widely as men. This concern, therefore, is expressed by the adoption of pro-active self-protection measures, which limit the access to this information. These practices may be related to a sense of insecurity and fear, fuelled by several episodes of online crime against women (i.e., sexual grooming, harassment or intimidation by cyber-bullies or stalkers) reported by the Italian mass media (Genta, Brighi \& Guarini, 2013). Also, other sources of statistical evidence confirm that women have good reason to be more caution in an online environment.

In 2014, the Italian National Institute for Statistics (ISTAT) reported that women in Italy are more often victims of cyberbullying than men (7.1\% of women versus $4.6 \%$ of men) (ISTAT, 2014). Moreover, the study carried out by Amnesty International showed that $16 \%$ of Italian women reported they had experienced online abuse or harassment one or more times (Dhrodia, 2017). In addition, the identified consistent gender differences can be understood by looking at the traditional role of women as the organisers and maintainers of the private sphere (Fortunati, 2007). Women's propensity to recognise and sort out social risks and take care of safety issues may also reflect in their online behaviour. In this sense, privacy management on Facebook can be regarded as a new dimension of digital housekeeping that has become an integral part of the domestic routines (Fortunati, 2018; Tolmie, Crabtree, Rodden, Greenhalgh \& Benford, 2007). All of this is well in line with Hoy and Milne (2010), who found that women perceive the consequences of online self-disclosure more severely than men; therefore, they manage their privacy setting in a more proactive way, focusing more on this kind of digital labour.

While the previous research has pointed out a tilt towards social privacy concerns, this study shows evidence that young Italian people have almost the same amount of concerns toward Facebook as a company. Studies from other countries have discovered that women's level of privacy concerns has considerably increased in the 
first decade of the 21st century (Hoy and Milne, 2010), which probably explains the relatively high level of institutional privacy concerns in our study. This heightened awareness may also stem from vivid public discussion, evolved around how Facebook collects a massive amount of data from its users (e.g., demographic details, personal information, interests, messages, pokes, likes, locations, etc.) and utilises them for commercial purposes. At the same time, we should keep in mind that privacy concerns are not so strong against third-party partners among young Italians. This makes us think that Facebook users are not yet well aware of the business model behind Zuckerberg's company or the fact that Facebook captures as much user data as possible to sell to third-party partners for commercial purposes. This commodification of user data has already been widely studied and associated with the idea of exploitation of digital labour (Fuchs, 2012).

It is worth highlighting that relatively high concerns against Facebook are not connected to the adjusting of privacy settings (i.e., those measured through the privacy index). In this connection, previous studies have talked about the privacy paradox (Taddicken, 2014), which shows the mismatch between the high level of privacy concerns and actual user behaviour. In contrast to concerns against other users, our analysis did not show statistical connections between concerns of individuals toward Facebook as a company and their levels of adjusting privacy settings. This can be understood by comparing the possible negative consequences of privacy loss, which could be perceived as much more immediate, tangible and damaging in the case of peer violation. Just like young people have increased their digital skills through trial and error among peers, more attempts and perhaps failures develop a greater awareness toward Facebook as a company and third-party partners.

Finally, the sample and data used in this study impose some limitations for findings, which are hardly generalisable. Like in many other studies on Facebook and privacy (Hoy \& Milne, 2010; Tufekci, 2008; Waters \& Ackerman, 2011), our research was conducted among university students, who are relatively highly educated and, hence, probably more aware of privacy issues than the general population. To further investigate the actual user behaviour on privacy matters, alternative methods and larger samples could be applied for different nationalities and cultures to better reveal the mechanism behind the personal choices regarding privacy settings and information disclosure.

Moreover, using qualitative methods of data collection and analysis in conjunction with survey methodology could be useful to better interpret the meaning of survey responses, investigate more in-depth strategies adopted by people to achieve various levels of intimacy on Facebook and negotiate the boundaries between the private and public sphere. In addition, it could be more appropriate to explore and challenge the idea of a capitalist exploitation of social media users. Perhaps this unpaid digital labour is motivated by the potential social benefits that users obtain in exchange for revealing their personal content on Facebook; however, this should not be ignored. In future research, mixed method studies that combine quantitative and qualitative approaches could complete the picture of users' motivation to engage in the voluntary production of online content and to disclose personal information to their Facebook friends and, sometimes, to strangers. Moreover, it could be interesting to investigate if people adopt any resistance practices to prevent an invasion of private spheres by the others. Lastly, we think that peer-surveillance (i.e., the practice of observing what others post on Facebook) deserves more scholarly attention. This is especially because, in sociological terms, peer monitoring has several negative and positive functions, such as: contact, discover and comparison (Albrechtslund, 2008; Andrejevic, 2005; Farinosi, 2011; Marwick, 2012). 


\section{References}

Acquisti, A., \& Gross, R. (2006). Imagined communities: Awareness, information sharing, and privacy on the Facebook. In G. Danezis, \& P. Golle (Eds.), Privacy enhancing technologies (pp. 36-58). Berlin, Heidelberg: Springer-Verlag.

Acquisti, A., Brandimarte, L., \& Loewenstein, G. (2015). Privacy and human behavior in the age of information. Science, 3476221), 509-514.

Albrechtslund, A. (2008). Online social networking as participatory surveillance. First Monday, 13(3).

Andrejevic, M. (2005). The work of watching one another: Lateral surveillance, risk, and governance. Surveillance \& Society, 2(4), 479-497.

Awan, F., \& Gauntlett, D. (2013). Young people's uses and understandings of online social networks in their everyday lives. Young, 21(2), 111-132.

Bach, N., Köhler, M., Hans-Liudger, D., Horvath, L., Schmidt, M., Pohoryles, R., \& Soffer, T. (2011). PRACTIS: Report on changing perceptions of privacy and the changing role of the State. Retrieved from http://www.practis.org/docs/D3\%204_final_report_20110725.pdf

Bartsch, M., \& Dienlin, T. (2016). Control your Facebook: An analysis of online privacy literacy. Computers in Human Behavior, 56, 147-154.

Bazarova, N. N. (2012). Public intimacy: Disclosure interpretation and social judgments on Facebook. Journal of Communication, 62(5), 815-832.

Bedi, M. S. (2013). Facebook and interpersonal privacy: Why the third party doctrine should not apply. Boston College Law Review, 54(1), 1-71.

Bellman, S., Johnson, E. J., Kobrin, S. J., \& Lohse, G. L. (2004). International differences in information privacy concerns: A global survey of consumers. Information Society, 20(5), 313-324.

boyd, d. (2012). Networked Privacy. Surveillance \& Society, 10(3-4), 348-350.

boyd, d. (2014). It's complicated: The social lives of networked teens. New Haven, CT: Yale University Press.

boyd, d., \& Ellison, N. B. (2007). Social network sites: Definition, history, and scholarship. Journal of ComputerMediated Communication, 13(1), 210-230.

boyd, d., \& Hargittai, E. (2010). Facebook privacy settings: Who cares? First Monday, 15(8).

Brandtzaeg, P. B. (2015). Facebook is no 'great equalizer': A big data approach to gender differences in civic engagement across countries. Social Science Computer Review, 35(1), 103-125.

Bruns, A., Burgess, J. E., Crawford, K., \& Shaw, F. (2012). \#qldfloods and @QPSMedia: Crisis communication on Twitter in the 2011 South East Queensland floods. Brisbane QLD, Australia: ARC Centre of Excellence for Creative Industries and Innovation, Queensland University of Technology.

Chambers, D. (2013). Social media and personal relationships: Online intimacies and networked friendship. London, UK: Palmgrave Macmillan.

Cho, S. H. (2007). Effects of motivations and gender on adolescents' self-disclosure in online chatting. CyberPsychology \& Behavior, 10(3), 339-345.

Cosenza, V. (2015). Facebook in Italia: 25 milioni al mese, 20 milioni al giorno, 21 da mobile. Retrieved from http://vincos.it/2015/02/20/facebook-in-italia-25-milioni-al-mese-20-milioni-al-giorno-21-da-mobile/

Couldry, N. (2012). Media, society, world: Social theory and digital media practice. Cambridge, UK: Polity Press. 
Dhrodia, A. (2017). Unsocial media: The real toll of online abuse against women. Retrieved from https://medium.com/amnesty-insights/unsocial-media-the-real-toll-of-online-abuse-against-women37134ddab3f4

Ellison, N. B., Vitak, J., Steinfield, C., Gray, R., \& Lampe, C. (2011). Negotiating privacy concerns and social capital needs in a social media environment. In S. Trepte, \& L. Reinecke (Eds.), Privacy online (pp. 1932). New York, NY: Springer.

Facebook. (2015). Facebook: A home for your Business. Retrieved from https://www.facebook.com/ads

Farinosi, M. (2011). Deconstructing Bentham's Panopticon: the new metaphors of surveillance in the web 2.0 environments. TripleC - Cognition, Communication, Co-operation, 9(1), 62-76.

Fogel, J., \& Nehmad, E. (2009). Internet social network communities: Risk taking, trust, and privacy concerns. Computers in Human Behavior, 25(1), 153-160.

Fortunati, L. (1996). The arcane of reproduction: Housework, prostitution, labor and capital. New York, NY: Autonomedia.

Fortunati, L. (2007). Immaterial labour and its mechanization. Ephemera: Theory \& Politics in Organization, 71 , 139-157.

Fortunati, L. (2018). How young people experience elderly people's use of digital technologies in everyday life. In S. Taipale, T. Wilska, \& C. Gilleard (Eds.) Digital technologies and generational Identity: ICT usage across the life course (pp. 102-118). Milton Park, UK: Routledge.

Fuchs, C. (2012). The political economy of privacy on Facebook. Television \& New Media, 13(2), 139-159.

Genta, M. L., Brighi, A., \& Guarini, A. (2013). Cyberbullismo: Ricerche e strategie di intervento. Milano, Italia: FrancoAngeli.

Goffman, E. (1959). The presentation of self in everyday life. New York, NY: Doubleday.

Gross, R., \& Acquisti, A. (2005). Information revelation and privacy in online social networks (The Facebook Case). Paper presented at the 2005 ACM Workshop on privacy in the electronic society, Alexandria, VA, USA. Retrieved from http://cui.unige.ch/tcs/cours/algoweb/2008/articles/privacy-facebook-grossacquisti.pdf

Gustafson, P. E. (1998). Gender differences in risk perception: Theoretical and methodological perspectives. Risk Analysis, 18(6), 805-811.

Hogan, B. (2010). The presentation of self in the age of social media: Distinguishing performances and exhibitions online. Bulletin of Science, Technology \& Society, 30(6), 377-386.

Hollenbaugh, E., \& Ferris, A. (2014). Facebook self-disclosure: Examining the role of traits, social cohesion, and motives. Computers in Human Behavior, 30, 50-58.

Hoy, M. G., \& Milne, G. (2010). Gender differences in privacy-related measures for young adult Facebook users. Journal of Interactive Advertising, 10(2), 28- 45.

ISTAT. (2014). Il Bullismo in Italia: Comportamenti offensivi e violenti tra i giovanissimi. Retrieved from http://www.istat.it/it/files/2015/12/Bullismo.pdf?title=Bullismo++tra

Joinson, A. N., \& Paine, C. B. (2007). Self-disclosure, privacy and the internet. In A. N. Joinson, K., Mckenna, T., Postmes, \& U. Reips (Eds.), The Oxford handbook of internet psychology (pp. 237-252). Oxford: Oxford University Press. 
Kietzmann, J. H., Hermkens, K., McCarthy, I. P., \& Silvestre, B. S. (2011). Social media? Get serious! Understanding the functional building blocks of social media. Business Horizons, 54(3), 241-251.

Kolek, E. A., \& Saunders, D. (2008). Online disclosure: An empirical examination of undergraduate Facebook profiles. NASPA Journal, 45(1), 1-25.

Lampinen, A., Lehtinen, V., Lehmuskallio, A., \& Tamminen, S. (2011). We're in it together: Interpersonal management of disclosure in social network services. Paper presented at the SIGCHI Conference on Human Factors in Computing Systems, Vancouver, BC, Canada. Retrieved from https://pdfs.semanticscholar.org/d86c/4dc108cf7262f56ce05a1dbfbada7e2299bf.pdf

Ledbetter, A. M. (2009). Measuring online communication attitude: Instrument development and validation. Communication Monographs, 76(4), 463-486.

Lenhart, A., Madden, M., Smith, A., Purcell, K., Zickuhr, K., \& Rainie, L. (2011). Teens, kindness and cruelty on social network sites: How American teens navigate the New world of digital citizenship. Retrieved from http://www.pewinternet.org/2011/11/09/teens-kindness-and-cruelty-on-social-network-sites/

Lewis, K., Kaufman, J., \& Christakis, N. (2008). The taste for privacy: An analysis of college student privacy settings in an online social network. Journal of Computer-Mediated Communication, 14(1), 79-100.

Liu, Q., Yao, M. Z., Yang, M., \& Tu, C. (2017). Predicting users' privacy boundary management strategies on Facebook. Chinese Journal of Communication, 10(3), 295-311.

Madden, M., \& Smith, A. (2010). Reputation management and social media: How people monitor their identity and search for others online. Retrieved from http://www.pewinternet.org/2010/05/26/reputationmanagement-and-social-media/

Marwick, A., \& boyd, d. (2014). Networked privacy: How teenagers negotiate context in social media. New Media \& Society, 16(7), 1051-1067.

Marwick, A. E. (2012). The public domain: Surveillance in everyday life. Surveillance \& Society, 9(4), 378-393.

Nissenbaum, H. (2004). Privacy as contextual integrity. Washington Law Review, 79(1), 119-158.

Nosko, A., Wood, E., \& Molema, S. (2010). All about me: Disclosure in online social networking profiles: The case of Facebook. Computers in Human Behavior, 26(3), 406-418.

Palfrey, J., Sacco, D., \& boyd, d. (2008). Enhancing child safety and online technologies: Final report of the internet safety technical task force to the multi-state working group on social networking of State Attorneys General of the United States. Retrieved from http://cyber.law.harvard.edu/pubrelease/isttf/

Palmieri, C., Prestano, K., Gandley, R., Overton, E., \& Zhang, Q. (2012). The Facebook phenomenon: Online self-disclosure and uncertainty reduction. China Media Research, 8(1), 48-53.

Rainie, L., \& Wellman, B. (2012). Networked: The new social operating system. Cambridge, MA: MIT Press.

Raynes-Goldie, K. (2010). Aliases, creeping, and wall cleaning: Understanding privacy in the age of Facebook. First Monday, 15(1).

Soffer, T., \& Cohen, A. (2014). Privacy perception of adolescents in a digital world. Bulletin of Science, Technology \& Society, 34(5-6), 145-158.

Stutzman, F., Gross, R., \& Acquisti, A. (2013). Silent listeners: Evolution of privacy and disclosure on Facebook. Journal of Privacy and Confidentiality, 4(2), 7-41.

Sun, T., \& Wu, G. (2012). Traits, predictors, and consequences of Facebook self-presentation. Social Science Computer Review, 30(4), 419-433. 
Taddicken, M. (2014). The 'privacy paradox' in the social web: The impact of privacy concerns, individual characteristics, and the perceived social relevance on different forms of self-disclosure. Journal of Computer-Mediated Communication, $19(2), 248-273$.

Thelwall, M. (2009). Social network sites: Users and uses. In M. Zelkowitz (Ed.), Advances in Computers (vol. 76, pp. 19-73). Amsterdam, Netherlands: Elsevier.

Thelwall, M. (2011). Privacy and gender in the social web. In S. Trepte, \& L. Reinecke (Eds.), Privacy online: Perspectives on privacy and self-disclosure in the social web (pp. 255-269). Berlin, Heidelberg: Springer.

Tolmie, P., Crabtree, A., Rodden, T., Greenhalgh, C., \& Benford, S. (2007, September). Making the home network at home: Digital housekeeping. In L. J. Bannon, I. Wagner, C. Gutwin, R. H. R., K. Schmidt (Eds.), ECSCW'07: Proceedings of the Tenth European Conference on Computer Supported Cooperative Work (pp. 331-350). London, UK: Springer.

Tufekci, Z. (2008). Can you see me now? Audience and disclosure regulation in online social network sites. Bulletin of Science, Technology \& Society, 28(1), 20-36.

Van Dijck, J. (2013). The culture of connectivity: A critical history of social media. New York, NY: Oxford University Press.

Vitak, J., \& Ellison, N. B. (2013). 'There's a network out there you might as well tap': Exploring the benefits of and barriers to exchanging informational and support-based resources on Facebook. New Media \& Society, 15(2), 243-259.

Waters, S., \& Ackerman, J. (2011). Exploring privacy management on Facebook: Motivations and perceived consequences of voluntary disclosure. Journal of Computer-Mediated Communication, 171), 101-115.

Weiqin, E. L., Campbell, M., Kimpton, M., Wozencroft, K., \& Orel, A. (2016). Social capital on Facebook: The impact of personality and online communication behaviors. Journal of Educational Computing Research, $54(6), 747-786$.

Youn, S., \& Hall, K. (2008). Gender and online privacy among teens: Risk perception, privacy concerns, and protection behaviors. CyberPsychology \& Behavior, 11(6), 763-765. 